\title{
La lucha de clases en Coronación de José Donoso y sus adaptaciones fílmicas
}

\section{The class struggle in José Donoso's Coronation and its film adaptations}

\author{
MÁRTON Árva \\ Universidad Eötvös Loránd (Budapest) \\ arvamarton@gmail.com \\ ORCID ID: 0000-0001-8193-0311
}

Resumen: El presente trabajo analiza la relación entre el texto y el contexto en el caso de Coronación (1957) de José Donoso y sus dos adaptaciones cinematográficas realizadas por Sergio Olhovich (México, 1976) y Silvio Caiozzi (Chile, 2000). Se observa la manera en la que el mismo argumento se relaciona con el contexto de la modernización chilena a mediados del siglo $\mathrm{XX}$, la desilusión con el poder estatal posrevolucionario en México tras 1968 y la transición a la democracia neoliberal en el Chile del nuevo milenio. El artículo argumenta que el motivo de la confrontación entre «maestros» $\mathrm{y}$ «sirvientes» sirve al propósito de abordar las consecuencias tanto psicológicas e individuales como colectivas y sociales que tienen las transformaciones socio-históricas en momentos y lugares distintos.

Palabras clave: adaptación filmica, neoliberalismo, ideología, lucha de clases, revolución mexicana, cine chileno, cine mexicano, José Donoso.

\begin{abstract}
This paper analyses the relationship between text and context in the case of José Donoso's Coronación (1957) and its two film adaptations, directed by Sergio Olhovich (Mexico, 1976) and Silvio Caiozzi (Chile, 2000), respectively. It observes the ways in which the same plotline connects to the context of the mid- $20^{\text {th }}$ century modernization process in Chile, the disillusionment with the post-revolutionary state power in Mexico after 1968, and the Chilean transition to neoliberal democracy in the new millennium. The article argues that by choosing the confrontation between «masters» and «servants» as a theme, these narratives address the psychological and individual as well as the collective and social consequences of sociohistorical transformations in different times and places.
\end{abstract}

Keywords: film adaptation, neoliberalism, ideology, class struggle, Mexican revolution, Chilean cinema, Mexican cinema, José Donoso. 


\section{INTRODUCCIÓN}

En su estudio Teoría y práctica de la adaptación, Robert Stam pone de relieve una serie de elementos que moldean la relación entre el texto y el contexto de una adaptación fílmica (2009: 92-101). En particular, el teórico estadounidense advierte que, durante el proceso de adaptación, el hilo narrativo y el entorno ficticio provenientes de una fuente novelesca se ven relacionados con los «discursos ideológicos y sociales» (2009: 95) asociados con el momento de la filmación. Este diálogo entre el texto y el contexto discursivo gana una importancia aún más destacada en los numerosos casos en los que la novela adaptada es publicada en una época o ambiente geográfico y socioeconómico diferente a los de la filmación. En tales ocasiones, la adaptación fílmica puede indicar las estrategias de «actualizar y reinterpretar» (2009: 93) o «reacentuar y transculturizar» (2009: 102) al texto literario, revelando las preocupaciones de los cineastas frente a sus propios ambientes actuales. De forma parecida, dichas actualizaciones buscan recalcar repeticiones y modificaciones que se dan entre los distintos contextos históricos y geográficos a los que el mismo argumento novelesco se ajusta. El presente trabajo propone demostrar que tales paralelos contextuales nos informan de la función cultural de una narrativa, compartida por la literatura y el cine, tomando como caso de estudio las dos adaptaciones cinematográficas de la novela chilena Coronación, escrita por José Donoso y publicada originalmente en 1957.

La hipótesis fundamental del presente análisis es que la misma trama enfocada en el choque entre «maestros»y «sirvientes» sirve al propósito de observar profundas transformaciones socioeconómicas y políticas en contextos sumamente distintos. Esta hipótesis se inspira en el argumento formulado por Stephen Buttes a propósito de $\mathrm{La}$ nana (2009), una película chilena enfocada en la vida cotidiana de una trabajadora doméstica (Buttes, 2014). Dicho estudio establece un paralelismo entre ciertos rasgos dramatúrgicos y argumentales de $L a$ nana y La chica del Crillón, una novela popular escrita por Joaquín Edwards Bello en 1935. Buttes concluye que ambas obras pueden leerse como parábolas sobre la integración de las clases vulnerables al orden social en diversos puntos de inflexión socioeconómica: el retroceso de la oligarquía rural frente a la naciente clase obrera en los años treinta y la flexibilización laboral en la democracia neoliberal de los años 2000. De manera parecida, las dos adaptaciones de Coronación -realizadas por Sergio Olhovich en 1976 en México y Silvio Caiozzi en 2000 en Chile- abordan el choque entre las clases privilegiadas decadentes y los grupos marginalizados en diferentes 
períodos y contextos nacionales, convirtiendo así el argumento donosiano en una herramienta apta para examinar en el cine la experiencia de vivir transiciones epocales.

\section{Perdiendo control sobre el futuro}

José Donoso fue un destacado miembro de la llamada «generación del 50», un grupo de escritores que provocó fuertes repercusiones en la vida intelectual de Chile en medio de bruscos cambios sociales debidos a la modernización económica del país ${ }^{1}$. Si bien este impulso industrializador conllevó unas dinámicas de reorganización socioeconómica a partir de los años 50, «por primera y única vez, la literatura chilena se convirtió en punto de discusión a lo largo del país» (Godoy Gallardo y Ahumada Peña, 2012: 104). A la delantera de este movimiento literario renovador, Coronación -la primera novela de Donoso- se fija en un momento de inflexión histórica y describe una serie de transformaciones en cuanto a la emergencia de nuevos valores sociales, cambios en las condiciones materiales y el surgimiento de rituales culturales inéditos para la sociedad chilena de ese entonces.

La novela relata los últimos meses de Elisa Grey de Ábalos, una viuda nonagenaria mentalmente desequilibrada que habita en una otrora espléndida residencia en Santiago de Chile. Postrada en cama debido al deterioro de su salud, doña Elisita es atendida por dos viejas criadas, Rosario y Lourdes, y es visitada regularmente por su nieto, Andrés Ábalos, un orgulloso hombre solitario de cincuenta años de edad. Sin embargo, este microcosmos se ve perturbado por la llegada de la sobrina ingenua de Lourdes, una campesina adolescente, Estela, quien había sido «prometida» a su tía por su difunta madre, por lo que se traslada a la casa de los Ábalos para cuidar de doña Elisita. La muchacha resulta ser una sirvienta obediente que se transforma involuntariamente en una femme fatale, dado que su belleza sencilla no solo atrae a don Andrés, sino también a Mario, un joven de clase baja trabajando en la pequeña tienda que provee de comida a la casa aristocrática. El deseo incontrolable que los dos hombres sienten por

\footnotetext{
${ }^{1}$ Como describen Simon Collier y William F. Sater, la industrialización en este período provocó una situación social ambigua cuyos efectos principales fueron el fortalecimiento de las clases medias, la concentración de bienes en manos de la élite industrializadora y, al mismo tiempo, la supervivencia de una élite rural terrateniente (2004: 264-286). El académico Óscar Galindo Villarroel resume este momento contradictorio refiriéndose al Chile de mediados del siglo XX como «Un país moderno. Semi rural y subdesarrollado, pero moderno e innovador» (2008: 102).
} 
la criada recién llegada pronto se vuelve en una fuerza destructiva, provocando el declive psicológico de don Andrés y la corrupción moral de Mario. Mientras el primero acaba enloquecido y dando la espalda al mundo, el segundo es cómplice de su hermanastro al asaltar la mansión de los Ábalos.

Evidentemente, Donoso describe un enfrentamiento entre personajes de diferentes clases sociales. Al mismo tiempo, la novela confronta las posiciones históricamente formadas con el encuentro palpable y encarnado de las personas que ocupan estos roles. Como observa uno de sus críticos, Coronación presenta «los efectos que tiene una norma de valores sociales inflexiblemente represivos sobre la base instintiva de la personalidad humana» (citado en Castillo-Feliú, 1980: 704). Es más, en vez de considerar las posiciones sociales como abstractas o universales, la novela trata minuciosamente los cambios socioculturales y económicos por los que estas se ven modificadas, indirectamente catalizando al enfrentamiento de los personajes y a la erupción de sus pasiones. La mayor parte de la trama se desarrolla en el espacio cerrado de la mansión de los Ábalos, un viejo y sombrío edificio lleno de recuerdos enterrados bajo gruesas capas de polvo. El escenario, junto con la lenta defunción de la abuela como elemento central, destaca la transición histórica como la fuerza motriz primordial de la narración. Enmarcado de dicha manera, el argumento de Coronación parece examinar cómo los valores heredados y abstraídos se ven moldeados al tomar forma en contextos socio-históricamente situados y desafiados por encuentros encarnados y vividos.

El texto de Donoso describe el pasado armonioso y el presente desmontable de personajes que representan un estilo de vida aristocrático decadente, una jerarquía social rígida y unas pautas de comportamiento conservadoras. A pesar de su enfermedad, doña Elisita mantiene su orgullo y su postura superior, constantemente recordando (o mejor dicho, reinventando) su noble herencia, o sea, su supuesto linaje real europeo. Del mismo modo, don Andrés estudió para ser abogado, al igual que su abuelo, pero prefiere no ejercer su profesión. Su personaje, como afirma Silvia Margarita Donoso, es el prototipo del «hombre de aproximadamente la mitad del siglo XX que podía vivir de sus rentas, sin tener la necesidad de trabajar» (2016: 106). La quietud temporal y el statu quo de la casa se completan con las dos criadas. Ellas llevan tanto tiempo en la residencia que don Andrés ni siquiera la recuerda sin ellas (Donoso, 1984: 10). Aun cuando Lourdes y Rosario, sirvientas de edad avanzada -y que mantienen poco contacto con el mundo exterior-, 
nunca cuestionan el orden de las cosas, los personajes que van llegando desde fuera de ese espacio íntimo desafían esas reglas. Cuando doña Elisita celebra sus 94 años con una fiesta, su alta autoestima contrasta con sus condiciones mentales y físicas. Esto llega a ser declarado por Carlos Gros, el médico de la familia y el único amigo de infancia de don Andrés: él simplemente se refiere a doña Elisita como una mujer desesperadamente loca. La viuda se ve completamente abandonada por la sociedad, como lo demuestra la constante disminución de la asistencia a sus fiestas, llegando a cero al final de la novela.

Asimismo, los nobles principios de don Andrés resultan extrañamente anacrónicos y, lo que es más importante, insostenibles cuando se pretende trasladarlos a la realidad física. Dedicando su tiempo a la lectura y al pensamiento, el nieto no solo es incapaz de establecer relaciones humanas satisfactorias, sino también de hacer frente a este fracaso. Percibe cualquier contacto fuera del bien protegido campo de la cultura erudita (es decir, sus lecturas y el club social que visita ocasionalmente) como una amenaza directa al «orden» y a la «civilización». Notablemente, su deseo por Estela lo angustia sobre todo porque anima fuerzas que están más allá de los límites de la esfera elitista racionalmente definida que él habita y controla. En primer lugar, supuestamente siente la pasión carnal más fuerte de su vida, lo que contrasta con sus rutinas puramente intelectuales y su estricta educación religiosa. En segundo lugar, y aún más molesto, este deseo está orientado a una mujer de clase baja, de piel oscura y llamativamente joven, es decir, a alguien que nunca será aceptada en el restringido mundo de la sociedad privilegiada. Finalmente, el tercer y más perturbador aspecto del deseo de don Andrés es que había sido «irracionalmente presentido» y «obscenamente anunciado» por su abuela demente antes de que él pudiera darse cuenta por sí mismo. Por lo tanto, el pánico que invade a don Andrés al reconocer esta pasión está motivado por la imposibilidad de asimilarla en su coherente cosmovisión. Incapaz de sincronizar sus tradiciones y valores heredados con sus recientes percepciones y afectos orientados por su entorno, don Andrés termina prefiriendo volverse loco y comienza a actuar de esta manera porque así «ninguno de sus dolores era efectivo, y todos los acontecimientos de esa noche, ficción» (Donoso, 1984: 187).

Miguel Ángel Náter nota que, en las primeras novelas de José Donoso, la alienación y el deterioro personal no solo «implican crisis del mundo» (2007: 152), sino también están relacionadas a «la decadencia del clan familiar»y, además, se refieren a la clase social 


\section{Márton Árva}

(2007: 154). Esta lógica metonímica está marcadamente presente en Coronación, ya que establece una relación entre el microcosmos de la vieja casona y el entorno social chileno. Visto desde esta perspectiva, el colapso emocional y psicológico de don Andrés corresponde a la desaparición de lo que la mansión Ábalos representa en la sociedad santiaguina. Ambas esferas - la mente cultivada del noble hombre y la antigua mansión- se confrontan con las fuerzas de impulsos reprimidos. Por consiguiente, la locura autoinfligida de don Andrés significa la aceptación de una derrota amorosa que es el reflejo de su fracaso social. Como señala Carlos, el respetado médico, en una de sus más significativas conversaciones con Andrés, al no haber logrado nada grande, profundo o satisfactorio en la vida, «el amor, entonces, es la única gran aventura que nos queda» (Donoso, 1984: 63). Por lo tanto, se sugiere que el último intento desesperado de Andrés de buscar la intimidad con Estela es un sustituto de sus logros en el campo social que ayudan a defender sus privilegios. De esta manera, puede esperarse que su fracaso en la aventura amorosa también provoque su desaparición en términos sociales. Esto se subraya en la novela por el hecho de que los moribundos doña Elisita y Andrés son los dos últimos miembros vivos del aristocrático linaje familiar de los Ábalos. Así, al ser rechazado por Estela (quien queda embarazada del hijo de Mario y no de el de Andrés), el noble heredero es testigo de la perdición de su linaje. De ahí que su pánico individual frente a la muerte llegue a asociarse con el miedo a la extinción de su familia y clase social privilegiada. Al fin y al cabo, es dicho temor el que le hace a Andrés recurrir al máximo auto-aislamiento: la locura voluntaria.

El miedo apocalíptico a la extinción se refuerza en el texto aún más por la marcada falta de una perspectiva que apunte hacia un futuro próspero. Por un lado, el tono del texto de la novela es sumamente nostálgico, describiendo la casa y sus habitantes como «viejos y rodeados de olvido» (Donoso, 1984: 9). Los muebles y objetos parecen ser reliquias de épocas pasadas. Además, dispuesto a revitalizar la mansión, don Andrés comienza a ordenar el ático inutilizado y a redescubrir con una de las criadas los restos olvidados de la historia familiar, proporcionándole la única auténtica fuente de felicidad. Es más, Coronación no solo incluye largos párrafos que detallan los recuerdos de don Andrés, sino que también describe de manera extensa recuerdos de Estela y Mario. La estrategia de Donoso es penetrar en las conciencias de varios personajes, motivando sus acciones por sus reflexiones sobre experiencias pasadas (CastilloFeliú, 1980: 702). De esta manera, cada personaje se convierte en 
una colección viva de recuerdos, con una tendencia evidente a mirar hacia atrás. En consecuencia, la mayoría de sus intentos de reconciliarse con el presente se articulan mediante acciones agresivas, delirantes o criminales. Finalmente, como el enloquecimiento de don Andrés muestra paralelismos incómodos con el de doña Elisita -ya que se sugiere que ella también «se volvió loca» después de un fracaso amoroso (al haber sido engañada por su marido)-, la condición de la abuela también puede interpretarse, en retrospectiva, como una decisión consciente de darle la espalda al mundo. Así, todas las reliquias y recuerdos de la casa, que apuntan a una época en la que doña Elisita estaba todavía en su sano juicio, parecen referirse al momento en el que sus nobles valores - a semejanza de los de don Andrés- estaban todavía en consonancia con su entorno. De ahí que las figuras de doña Elisita y don Andrés evocan el comienzo y el final de un largo cambio histórico en la sociedad chilena: la desaparición de la oligarquía agrícola tradicional frente a la modernización (Daniels, 2013: 2). En resumen, teniendo en consideración este contexto histórico, el marcado temor de don Andrés a la extinción y su terror al hecho de que «él no volvería a existir más que en su antigua forma de cadáver animado» (Donoso, 1984: 109) pueden entenderse no solo como una caída individual, sino también en referencia a la decadencia de su noble familia, y, metonímicamente, marcando el fin de todo un orden social en el que se podía sostener su forma de vida.

Contrariamente, Estela, Mario y René son representantes de las clases bajas constantemente enfrentadas con futuros inciertos, lo que se ve expresado por su temor a tener hijos. A diferencia de don Andrés, ellos llevan una herencia traumática con rupturas familiares y un deseo persistente de escapar. Sin embargo, estos personajes desafortunados no pueden evitar transmitir sus desgracias a la siguiente generación, como lo sugieren tanto el embarazo no deseado de Estela como el de Dora, la sufriente esposa de René. Así, la novela de Donoso termina presentando el ineludible paso del tiempo a través del punto de vista de aquellos para quienes este proceso no connota más que perder un pasado glorioso o esperar un futuro precario. Las nuevas oportunidades que brinda el proceso de la urbanización industrial resultan ocultas a los ojos tanto de la aristocracia decadente - viviendo de sus antiguos privilegios, sus tradiciones anticuadas y sus normas opresivas- como de los de clase baja que hacen frente a promesas fallidas de prosperidad, una tras otra, y residen en barrios empobrecidos en las afueras de la ciudad. Al final, ambos tipos de crisis -la de don Andrés y la de Estela, Mario 
y su hermano, René- se asocian con las posiciones sociales de los perdedores en el contexto del proceso modernizador.

$\mathrm{Al}$ mismo tiempo, a pesar de su tono relativamente sombrío y su mundo cerrado, Coronación incluye breves miradas a los ganadores de la mencionada transición histórica. Por ejemplo, Carlos Gros, retratado como triunfador en su vida profesional y felizmente casado a pesar de sus constantes aventuras amorosas, introduce un punto de vista que contrasta espectacularmente con el del resto de los personajes. Dado que la representación de este personaje constituye un factor crucial en el análisis de las adaptaciones fílmicas, atenderé este aspecto más adelante. Pero antes de eso, cabe destacar otro episodio revelador. Después de los primeros comentarios obscenos de doña Elisita que insinúan el deseo que don Andrés siente por Estela, el soltero escandalizado se dirige al Club de la Unión, donde charla con sus compañeros de clase alta sobre la ópera y el arte, hasta que «un grupo de hombres jóvenes con aire de que el mundo les pertenecía» y que «eran serios y conscientes, sin dudar ni siquiera por un segundo que el futuro del país caería en sus manos» se instalan cerca de ellos (Donoso, 1984: 89). Aparentemente, se trata de una reunión de gerentes y jóvenes empresarios «con sus trajes grises y sus camisas blancas, casi idénticos unos a otros» (1984: 89), en la cual los hombres desconocidos discuten sobre política, mercados bursátiles, inversiones arriesgadas y balances financieros. Tras encontrar una tremenda falta de grandeza en estos tipos de conversación y «sabiéndolos horrorosamente equivocados en sus valores» (1984: 8990), don Andrés se escapa repentinamente de la escena. Sin embargo, esta breve ojeada al exterior del microcosmos de los Ábalos echa luz sobre el contexto sociopolítico circundante: la larga transición del dominio aristocrático-oligárquico al capitalismo industrializado liderado por la clase empresarial. Con la excepción de este episodio, Coronación es contada a través de los ojos de individuos cada vez más marginados que no consiguen sacar provecho de esta transformación socioeconómica; por lo que, acaba siendo una sombría historia sobre los desajustes entre las expectativas internas y la realidad histórica externa. Los casos entremezclados de don Andrés, Estela, Mario y René exponen diferentes perspectivas sobre un conjunto complejo de conflictos, dando lugar a un abigarrado cuadro psicológico sobre los tiempos inexorables del cambio social.

El notable recurso narrativo que Donoso aplica para elaborar este cuadro es lo que Guillermo I. Castillo-Feliú llama «omnisciencia selectiva múltiple» (1980: 700). Esta consiste en filtrar los acontecimientos a través de los puntos de vista de diferentes 
personajes, uno tras otro, dando voz a sus pensamientos como si un narrador omnisciente circulara entre sus mentes. Como el académico explica, el efecto inmediato de este enfoque narrativo es doble. Por un lado, se ocupa de múltiples subjetividades, a menudo antagónicas entre sí, lo que representa el choque entre clases sociales opuestas de una manera más equilibrada. Por otro lado, al hacer hincapié en el mundo interior de los personajes, el método textual expone su «falta de contacto y expresión emotiva» (Castillo-Feliú, 1980: 704). Así, dicho procedimiento provoca que la representación de los acontecimientos tenga un carácter curiosamente fragmentado y multifacético. Al mismo tiempo, transferir este acercamiento al campo de la expresión cinematográfica - un medio constituido por (inter)acciones visibles y audibles- es un desafío complejo, como evidencian las obras de Sergio Olhovich y Silvio Caiozzi.

\section{DELIRIO Y DESILUSIÓN}

La primera adaptación cinematográfica de Coronación se estrenó en México en 1976, en un contexto discursivo caracterizado por el desencanto con la ideología nacionalista del Estado posrevolucionario. Desde el establecimiento de una industria fílmica en México en los años 30, el Estado utilizaba el cine como herramienta para promover la idea de que la reconciliación nacional y la integración de la población en una sociedad modernizada era posible a través del gobierno unipartidario. No obstante, a partir de mediados del siglo, estas ideas empezaron a ser ampliamente criticadas por intelectuales, escritores y cineastas que vieron el fracaso del proyecto posrevolucionario como «una forma de psicosis en la sociedad mexicana» (Acevedo-Muñoz, 2003: 62) ${ }^{2}$. Este discurso -moldeado, entre otros, por El laberinto de la soledad de Octavio Paz y las películas de Luis Buñel-entrelazaba la crítica del nacionalismo estatal con un acercamiento expresivo inspirado por el psicoanálisis.

El director de Coronación, el soviético-mexicano Sergio Olhovich, se socializó como cineasta en este ambiente cultural e ideológico turbulento, en el cual «el estado crítico del cine nacional era un reflejo del estado de la política nacional» (Acevedo-Muñoz, 2003: 150). Su adaptación evoca intermitentemente la obra de Buñuel y otros cineastas modernos europeos, transformando el conflicto interior de don Andrés en un deseo sexual irresistiblemente perverso, donde mezcla la narración realista con una serie de

\footnotetext{
${ }^{2}$ Todas las traducciones del inglés son mías.
} 
irrupciones de imágenes mentales del protagonista ${ }^{3}$. Este aspecto connota una alteración radical del enfoque de la novela durante el proceso adaptador. La transformación de la técnica narrativa de Donoso -que aplica múltiples puntos de vista simultáneos- en un modo de contar la historia que permite acceder a la subjetividad de un solo protagonista, don Andrés (Ernesto Alonso), llama la atención sobre el conjunto de sus tormentos interiores más que sobre el choque entre diferentes esferas sociales. En consecuencia, Olhovich exterioriza el mundo subjetivo de don Andrés, se aventura a retratar su mente angustiada y, a su vez, erotiza la imagen de Estela, convirtiéndola en el objeto del deseo de prácticamente todos los hombres en el filme. Si bien la película matiza la figura del protagonista solterón con monólogos en voz en off, editados a partir del texto original de Donoso, no recurre a ningún recurso formal para abordar la experiencia subjetiva de la criada taciturna (Leticia Perdigón). En cambio, Estela queda expuesta a la mirada de los personajes masculinos, por ejemplo, cuando en una reunión improvisada de hombres viejos admira unánimemente sus piernas descubiertas en la fiesta de doña Elisita (Carmen Montejo). Estos aspectos hacen que la narración fílmica sea estructurada alrededor del mundo interior de don Andrés.

En lugar de aspirar a una representación «equilibrada» del conflicto social, como lo hace Donoso, Olhovich tiende a presentar incluso los momentos más insignificantes de una manera muy distorsionada: solo a través de la perspectiva del protagonista masculino. Como una confesión íntima en off, don Andrés informa a los espectadores que ya había intentado suicidarse cuando se había sentido desesperadamente perdido con el mundo exterior. Este motivo, completamente ausente de la novela de Donoso, pone en evidencia la lucha mental y psicológica del personaje como un asunto individual-particular, más que como una tensión estructural que involucra el entorno socio-histórico. Al contrario, el don Andrés de Olhovich percibe poco antagonismo social y, cuando finalmente lo hace, esto se ve meramente provocado por los celos que siente hacia

\footnotetext{
${ }^{3}$ Emilio García Riera establece un paralelismo entre Coronación de Olhovich y Ensayo de un crimen de Buñuel (1955), ya que ambas películas se basan en el retrato de un hombre de mediana edad (interpretado en ambos casos por el actor Ernesto Alonso) cuya mente está perturbada por sus incontrolables deseos sexuales (García Riera, 1995: 152). Además, como explica András Bálint Kovács, subrayar el carácter subjetivo de la trama y permitir que una serie de escenas con un estatus mental ambiguo interrumpa la acción, era un rasgo común del cine moderno europeo (Kovács, 2007: 62-65).
} 
Mario. Es un miembro de la élite mexicana, incuestionablemente rico y exitoso, y aparentemente su único problema es su inestabilidad mental que es el resultado de su relación frustrada con su abuela y de los traumas sufridos en el pasado.

Estos últimos están minuciosamente detallados en la película por una serie de flashbacks, llenos de humillaciones y ansiedades que transportan al espectador a la infancia de don Andrés y que progresivamente irrumpen en el mundo de la acción narrativa. Este recurso puede identificarse como la diferencia más marcada entre la narración literaria y la adaptación fílmica. Aunque Donoso también incluye capítulos en la novela que describen los recuerdos de don Andrés sobre sus traumáticos encuentros con un riguroso sacerdote católico y un grupo de alumnos de la escuela primaria, estos episodios solo sirven para fundamentar los sentimientos del personaje en su biografía y no para confluir con sus acciones en el presente. Además, como don Andrés se enfrenta repetidamente a su «yo» infantil en la versión cinematográfica mexicana, comienza a discutir con él y acaba demostrando su valentía como si fuera un adolescente (imaginado) que acosa a Estela. En definitiva, la confusión entre la realidad interior y exterior de don Andrés se completa cuando, en la grotesca secuencia del desenlace, se une al niño que los espectadores conocen como su «yo» más joven al lanzar origami al cadáver de doña Elisita. Es más, Olhovich muestra a don Andrés en situaciones ambiguas que pueden interpretarse como imágenes mentales en su totalidad. Por ejemplo, en un episodio ya mencionado, el caballero se pone algunas ropas antiguas -que parecen ser disfraces- de un estuche polvoriento en el ático y se involucra en una pelea de almohadas con su «yo» más joven. Además, en la escena que sigue, comienza a molestar a Estela, empujándola contra la pared y acariciándola agresivamente. Sin embargo, el tono alegre de la secuencia, el extraño disfraz y el hecho de que Estela no parece guardar rencor después del incidente sugieren que este evento solo ocurre en la imaginación de don Andrés. Volviendo a la secuencia final, cuando el hombre inquieto le cuenta a Carlos su aventura con Estela y se refiere a un sofá vacío como si estuviera sentada allí, los espectadores tienen comprobado que su locura es auténtica. A diferencia de la versión novelesca, el don Andrés de Olhovich sufre de una psicosis verdadera, lo que se ve destacado por la última imagen de la película: un fotograma que muestra la macabra sonrisa de don Andrés con la voz de la sirena de una ambulancia que se aproxima. 
Por tanto, la interpretación de Olhovich se niega a aplicar un punto de vista narrativo plural y multifacético y, en consecuencia, hace poco por recrear el vínculo, observado en la novela, entre el colapso mental de don Andrés y la perdición del linaje aristocrático de los Ábalos, también simbolizado por la mansión disuasoria. En particular, cuando el nieto perturbado termina deseando abiertamente la muerte de doña Elisita en lugar de preocuparse por la extinción de su familia (y, por tanto, de sus privilegios), expresa un odio genuino profundamente arraigado en una historia familiar conflictiva. Los espectaculares planos generales que retratan la antigua mansión desde el exterior, «entre edificios modernos en la calle Londres» (García Riera, 1995: 152) en la Ciudad de México, también están encuadrados de tal manera que, en lugar de aludir a la progresiva desaparición del poder de sus habitantes, acentúan la sensación de estar en desacuerdo con la realidad circundante. Visto desde arriba, la sombría villa aristocrática de los Ábalos se ve empequeñecida por las modernas vecindades y las casas tan altas y poderosas que ni siquiera caben en el encuadre.

$\mathrm{Al}$ mismo tiempo, este gesto de omitir el contexto sociopolítico y romper los lazos entre el microcosmos doméstico y el entorno histórico también ofrece una lectura del filme que lo relaciona con una transición epocal dentro del marco del ambiente mexicano. Si la novela de Donoso incorpora una ojeada breve al entorno social circundante a la casa de los Ábalos en el episodio en donde Andrés se encuentra con un grupo de jóvenes empresarios, esta mirada momentánea al contexto es ofrecida al espectador de la película de Olhovich de otra forma: cuando René y su esposa Dora atraviesan una multitud reunida en las calles de la Ciudad de México. En esta instancia, el filme se enfoca en una poderosa marcha popular y se introducen varias tomas documentales en el largometraje de ficción, lo que se demuestra por el hecho de que muchos transeúntes sonríen y saludan al lente de la cámara. Como resultado, la escena acaba evocando a las bien conocidas secuencias que habían documentado las manifestaciones del Movimiento Estudiantil un par de años antes ${ }^{4}$. Estas protestas a finales de los años 60 dieron forma al descontento que estaba produciendo la organización posrevolucionaria y que ya estaban presentes en las críticas de Paz y Buñuel. Sin embargo, el poder estatal respondió a estas movilizaciones populares con una

\footnotetext{
${ }^{4}$ Estas secuencias grabadas por los estudiantes de la facultad universitaria de cine (el recién fundado CUEC de la UNAM) se dieron a conocer en el documental titulado El grito (1968).
} 
represión inexorable, cuyo trágico momento culminante fue la llamada masacre de Tlatelolco en 1968 (Vázquez Mantecón, 2016) 5 . Estos acontecimientos provocaron el reconocimiento colectivo de la imposibilidad de construir una sociedad posrevolucionaria más justa y dieron lugar a una desilusión profunda con respecto a la ideología nacionalista.

En resonancia con tales preocupaciones, la secuencia mencionada de Coronación rebate las implicaciones que las imágenes de la marcha callejera pudieron referirse a una manifestación por el cambio social y político. Al contrario, la cámara se aleja de la avalancha de gente y revela que, de hecho, René y Dora no están en una manifestación, sino meramente han encontrado una multitud de personas que van saliendo de un estadio después de un partido de fútbol. René entonces pregunta a un transeúnte sobre el resultado final, desacreditando por completo las referencias a un posible aspecto político de la escena. De esta manera, la película de Olhovich pone en relieve la ausencia de una transformación social, reflexionando sobre la pérdida de las esperanzas por la llegada de una modernidad próspera y justa, marcando así una nueva etapa en el proceso de construcción de la nación.

Desde esta perspectiva, Coronación forma parte de una serie de películas mexicanas de este período en las que los mencionados sentimientos de desencanto político tenían eco. Charles Ramírez Berg describe varios cambios institucionales, ideológicos y temáticos que redefinieron el panorama cinematográfico mexicano a principios de los años 70. Entre ellos, se destaca la oleada de nacionalizaciones durante el sexenio de Luis Echeverría (1970-76) y la promoción de un modelo cinematográfico que reinsertaría al país en el circuito internacional de festivales prestigiosos. Estos procesos dieron lugar a la rearticulación de géneros y estereotipos, introduciendo una era de películas enajenadas y desilusionadas que el historiador de cine llama, parafraseando el ya mencionado texto de Octavio Paz, «el cine de la soledad» (Ramírez Berg, 1992). Estas películas de autor se caracterizaban por un aire ominoso y ansioso, y por una preocupación por la represión y la explotación de las clases bajas, así como por las insuperables desigualdades de género y raza que fracturaban la sociedad mexicana en el contexto del fracaso de la Revolución.

\footnotetext{
${ }^{5}$ En la noche del 2 de octubre de 1968, dos semanas antes del comienzo de los Juegos Olímpicos de 1968 en la Ciudad de México, los soldados del ejército nacional dispararon a una multitud pacífica de seis mil manifestantes antigubernamentales en la Plaza de las Tres Culturas, en el barrio de Tlatelolco.
} 
Notablemente, varias de estas películas se fijan en el abuso de las empobrecidas sirvientas por parte de personajes poderosos y privilegiados, líderes del orden social poscolonial patriarcal ${ }^{6}$.

Incorporando este acercamiento crítico, la adaptación de Olhovich llama la atención al estancamiento social de la época. Por ejemplo, cuando doña Elisita grita delirantemente maldiciendo la Revolución, afirmando fervientemente que «ya no respetan a los señores» y que «este país se ha convertido en un desastre». Esto contradice espectacularmente el hecho de que la riqueza y los privilegios de su familia son prácticamente incuestionables a lo largo de la película. Dicho elemento se acentúa aún más en la secuencia culminante en el desenlace: la «coronación» de doña Elisita por Andrés y las dos fieles sirvientas que se desenvuelve en paralelo al robo. Donoso describe esta extraña ceremonia dionisíaca como una escena desgarradora. En la novela, mientras intentan consolar a la agonizante nonagenaria por no tener ningún invitado en su día de santo, las dos criadas borrachas le dan una corona, hecha por Lourdes con partes rotas de joyas que había estado recogiendo en la casa. Además, le ponen a doña Elisita una túnica que puede haber sido gloriosa, pero que se ha vuelto muy andrajosa a lo largo de los años. En contraste con esto, Olhovich escenifica un ritual auténticamente pomposo en una habitación ricamente adornada con una colorida decoración y convierte la cama de doña Elisita en un verdadero altar barroco, hecho de oro brillante, delante del cual ella aparece como una santa religiosa adorada. Sin duda, la escena es evidentemente grotesca, sobre todo por la actitud inmadura de las viejas criadas, el atribulado Andrés y la presencia de su «yo» infantil. Sin embargo, lo que esta secuencia expone es, de nuevo, una serie de delirios extravagantes y no un adiós a una prosperidad social.

Por lo tanto, ocultando la decisiva transformación socio-histórica hallada en el trasfondo de la novela original de Donoso, la adaptación

\footnotetext{
${ }^{6}$ Uno de los primeros ejemplos es Juego de mentiras (1967) de Archibaldo Burns, que ofrece una mirada al mundo interior de una mujer víctima de un entorno terriblemente hostil y machista. Rosa, de José Estrada, un segmento de una película antológica (Siempre hay una primera vez, 1971), cuenta cómo una sirvienta es maltratada por prácticamente todos los hombres que se cruzan en su camino y termina violada por su propio novio. Las cautivas (1973), de José Luis Ibáñez, muestra cómo dos mujeres -empleada y patrona- se pelean entre sí para después verse sometidas las dos a un hombre manipulador. Además, Los pequeños privilegios (1978), de Julián Pastor, construye con dolorosa exactitud el contraste entre el embarazo de una trabajadora doméstica y el de su patrona.
} 
mexicana de Coronación sitúa sus principales acontecimientos en un campo mental perturbado en el que los traumas individuales y las realidades sociales son cada vez más indistinguibles. De este modo, la versión de Olhovich muestra al México posterior al 68 como un país atrapado en un doloroso statu quo, donde la posibilidad de reformas y movimientos sociales ha dado paso al aislamiento. Teniendo como punto de referencia social la violenta represión del Movimiento Estudiantil, la desilusión con las promesas de la Revolución y el reconocimiento correspondiente del fracaso del Estado en la construcción de una nación mexicana más solidaria, la adaptación cinematográfica articula una transición hacia la introversión frustrada.

\section{TRAUMÁTICA TRANSICIÓN}

A diferencia de la película de Olhovich, la segunda adaptación de Coronación, realizada en Chile en 2000, opta por seguir la retórica de la novela más de cerca. En lugar de destacar las experiencias subjetivas de un don Andrés mentalmente perturbado, Silvio Caiozzi -un viejo amigo y colaborador de José Donoso ${ }^{7}$ - expone en su adaptación una transformación socioeconómica en la que la familia Ábalos rechaza participar. La película expone esta idea directamente en sus primeras imágenes. Doña Elisita (María Cánepa) está hipnotizada por una antigua fotografía suya, que la muestra como una bailarina de boleros. Está tan profundamente inmersa en la evocación nostálgica de la música generada por dicho instrumento que no percibe las palabras de su nieto llamándola. Don Andrés (Julio Jung) tiene que quitarle la imagen para que finalmente pueda dirigirse a la dama. Esta secuencia, que se despliega como fondo de los créditos del título, introduce el tema de un pasado ya frágil pero tenazmente sobreviviente. Más adelante en la escena, Andrés le pide a su abuela de que firme un cheque de pago. Sin embargo, la nonagenaria es demasiado débil para hacerlo, pues el heredero le tiene que llevar la mano. Esta combinación de inercia y poder fundamenta el discurso de la película sobre una inflexión histórica ${ }^{8}$.

\footnotetext{
${ }^{7}$ Además de Coronación, el director realizó otras dos adaptaciones de los textos de Donoso: el mediometraje de vídeo, Historia de un roble solo, en 1982, y el largometraje, Cachimba, en 2004 (Gatti, 2013: 29-30). Además, escribieron juntos el guion de La luna en el espejo, dirigida por Caiozzi y estrenada en 1990. Donoso consideró esta película «la historia de Coronación mirada desde otro punto de vista» (citado en S. M. Donoso, 2016: 113).

${ }^{8}$ Jannie Irene Daniels ofrece otra lectura plausible de la secuencia inicial al afirmar que esta introduce «la abundancia pasada y el declive financiero presente como un tema significativo en la película» (Daniels, 2013: 5).
} 
Reubicando el argumento prácticamente inalterado del texto original sobre el telón de fondo de la transición chilena a la democracia, Caiozzi se propone crear una estructura más balanceada, parecida a un cuadro social, que evoca el complejo juego de la novela con las perspectivas narrativas. Acentuando el choque entre los distintos grupos sociales, la película chilena explora cuidadosamente sus respectivas culturas materiales y sus rituales. No solo muestra reuniones de parientes aristócratas, partidos de fútbol de clase baja y comidas de criadas, sino que también ofrece ojeadas de una fiesta popular en un club nocturno y una noche solitaria en una sala de biblioteca de clase alta. La marcada co-presencia de prácticas culturales, originadas en diferentes períodos y esferas sociales distantes, se enfatiza aún más por lo que puede considerarse una versión cinematográfica de la ya mencionada «omnisciencia selectiva múltiple» de Donoso: el collage de estilos fílmicos disímiles, asociados a cada uno de los personajes principales. Notablemente, las tramas de don Andrés, Estela y Mario movilizan distintas series de herramientas estilísticas. El soltero amargado se ve principalmente entre una colección de objetos antiguos, propensos a aparecer en secuencias con poca iluminación, con movimientos de cámara relativamente lentos y acompañados de música clásica. Por el contrario, las escenas de la joven trabajadora doméstica convocan una especie de estilo telenovelesco con luces glamurosamente suaves, zums ligeros, colores saturados y emotivas melodías de guitarra. Por último, las imágenes que presentan a los criminales de clase baja -Mario (Paulo Meza) y su medio hermano- que aparecen sobre todo en los barrios pobres dominados por el hormigón gris y otros materiales baratos, son tomas temblorosas grabadas con una cámara a mano, normalmente acompañadas de música de baile popular o hip-hop urbano. Lo más interesante es que cuando estos hilos narrativos se cruzan, los rasgos estilísticos también se mezclan, como en el caso de la escena del robo al final de la película la cual se muestra con una iluminación tenue y movimientos de cámara más intensos.

En consecuencia, la segunda adaptación fílmica se abstiene de establecer una jerarquía estricta entre los personajes en términos de su importancia en la narrativa. En cambio, se aborda el trasfondo emocional y biográfico de Estela, doña Elisita, Mario, René, Carlos y Lourdes, así como el de don Andrés, aunque su mundo interno apenas se expone en la pantalla (con la excepción de dos flashbacks de don Andrés y doña Elisita). Por lo tanto, en lugar de comprometerse con el tema del declive individual, Caiozzi destaca los fenómenos sociales del abandono y el aislamiento como los motivos primordiales 
de la caída de la familia noble y del fracaso de los personajes pertenecientes a la clase trabajadora. Esto salta a la vista especialmente si comparamos la figura de don Andrés en las dos películas. En la adaptación chilena, en lugar de estar mentalmente perturbado, el caballero se muestra meramente deprimido por su incapacidad para establecer una relación mutuamente satisfactoria con Estela (Adela Secall). Está absorto en un largo período de autocompasión, intoxicado en su antiguo dormitorio y paralizado por la decepción, ya que Estela lo rechaza. Así, cabe destacar que no es la conmoción de sus recuerdos inquietantes, sino la pérdida de algo absolutamente palpable lo que don Andrés tiene que enfrentar en la secuencia final de la película. Puesto en escena de una manera melodramática, el desenlace muestra cómo el solterón observa que tanto su riqueza como su amor le son quitados lentamente, mientras Estela sale de la casa del lado de Mario. Por lo tanto, más que loco, en la interpretación de Caiozzi, don Andrés está genuinamente derrotado. Debido a estas decisiones adaptativas, la segunda versión fílmica se centra en las interacciones sociales en vez de en los destinos individuales. Este rasgo sobresale al observar la visión de Caiozzi sobre la transición hacia la democracia y la globalización capitalista.

Tras haber estudiado cine a finales de los años 60 y estrenando sus primeros largometrajes ya bajo el régimen autoritario del general Pinochet, Caiozzi pertenece a una generación que experimentó el paso de Chile de una dictadura militar culturalmente conservadora y represiva a una joven democracia que aspiraba a reformar sus instituciones políticas, pero dejando casi intacta la economía de libre mercado del antiguo régimen 9 . Durante este contradictorio período transitorio -que comenzó cuando Patricio Aylwin, el sucesor de Pinochet elegido democráticamente, asumió el cargo en 1990- Chile fue sacudido por una serie de transformaciones. Entre ellas, los

\footnotetext{
${ }^{9}$ La doctrina político-económica del neoliberalismo, empleada por primera vez en el Chile bajo el régimen de Pinochet, se basa en la idea de «que la mejor manera de avanzar en el bienestar humano es liberando las habilidades empresariales individuales dentro de un marco institucional caracterizado por fuertes derechos de propiedad privada, libre mercado y libre comercio» (Harvey, 2007: 2). En su mayor parte, las reformas neoliberales han significado una preferencia por la privatización, la desregulación del mercado y la defensa de la libre empresa. Así pues, el ajuste al neoliberalismo ha conllevado la creación de un mercado en el que las medidas proteccionistas se retiran y se ven sustituidas por un control estatal más débil, y las empresas y corporaciones de propiedad privada tienen más libertad para crecer, competir y ampliar su red comercial (Harvey, 2007).
} 
intentos de hacer frente a las anteriores violaciones de los derechos humanos, las iniciativas que promovían la reincorporación a la sociedad de personas que vivían en el exilio y, no menos importante, un espectacular auge del mercado de automóviles y electrodomésticos extranjeros, acompañado de la generalización del consumismo y el individualismo (Cavallo, Douzet y Rodríguez, 2007: 17-25).

Como afirman Ascanio Cavallo, Pablo Douzet y Cecilia Rodríguez:

Una sociedad que por muchas décadas había reservado la cima de la escala de valores a los pobres y a los trabajadores, de pronto pasaba el prestigio a las manos de los empresarios, los ricos y los audaces. El deseo de progreso material parecía tomar venganza contra los sueños de progreso cultural de los años 50, 60 y 70 (2007: 25-26).

Estrenada a finales de este período transitorio, poco después de que Pinochet regresara al país de Londres (donde el dictador había vivido casi dos años bajo arresto domiciliario) ${ }^{10}$, la segunda versión fílmica de Coronación sitúa la trama de la novela en medio de extensos cambios relacionados a la ideología, los estilos de vida y las costumbres cotidianas.

La crítica cultural Nelly Richard describe la transición a la democracia neoliberal chilena como un proceso marcado por «los ritmos exacerbados de la globalización capitalista, cuyo promiscuo régimen de comercialización disuelve jerarquías de valores y significados trascendentes» (Richard, 2004: 10). Extrañamente resonantes con esta observación, las metáforas más contundentes de la obra de Caiozzi -que juegan un papel central en la puesta en evidencia de los antagonismos sociales, generacionales y culturales-, son los automóviles. Explícitamente expuestos en un anuncio televisivo reproducido en su totalidad en la pantalla, los coches, por un lado, representan la promesa de un estilo de vida libre, rápido, alegre y aventurero. Estos son los valores que Carlos Gros, el médico de la familia, glorifica abiertamente cuando lleva a don Andrés a un recorrido en su lujoso coche deportivo. En contraposición, este

\footnotetext{
${ }^{10}$ Después de que un referéndum lo obligó a retirarse de la presidencia, el general Pinochet continuó siendo el líder formal del Ejército de Chile hasta marzo de 1998. Esto presentó una amenaza constante «psicológicoinstitucional» para el proceso de transición democrática (Cavallo, Douzet y Rodríguez, 2007: 20-21).
} 
último utiliza un viejo automóvil que tiene la forma de una caja, y se aísla en él como si se tratara de un refugio que le proporciona soledad y protección frente a la sociedad. Su rareza y sus tormentos interiores se exteriorizan en las secuencias que lo muestran conduciendo por el turbulento tráfico de Santiago. Disfrutando de las melodías clásicas de la radio de su coche o dejándose sumergir en un torrente de recuerdos, don Andrés no se adapta a las normas del tráfico. De hecho, es insultado recurrentemente por los demás conductores y termina en situaciones peligrosas. Además, su coche simboliza su antagonismo frente a los personajes de la clase obrera. Por ejemplo, cuando se dirige a las afueras de la ciudad en busca de Mario, un grupo de niños pobres que aparentemente ven tales bienes de consumo solo en la televisión, terminan arañando la carrocería del coche con piedras afiladas y golpeando sus neumáticos. Por otra parte, las características de su vehículo acaban por simbolizar sus torpes esfuerzos en el campo del amor, sobre todo en comparación con Mario, su rival que finalmente logra seducir a Estela. Notablemente, en la escena que muestra a don Andrés dándose cuenta de su derrota, el noble misántropo ve a los jóvenes amantes a través del parabrisas de su coche desmañado. Al mismo tiempo, la recién formada pareja de adolescentes hace un recorrido romántico en la ágil moto de Mario antes de quedar besándose fervientemente a las puertas de la mansión Ábalos. Así, los vehículos -no solo unas de las novedades consumistas más llamativas de los años 90 y 2000, sino también nuevos medios de la expresión individual- vienen a indicar actitudes psicológicas, oposiciones sociales y generacionales, y también rivalidades viriles en el filme.

Por otro lado, interpretado con el telón de fondo de la transición a la democracia neoliberal, los automóviles son propensos a prometer atajos para mejorar la calidad de vida. Así, su versatilidad física también se refiere a la mayor movilidad social que la naciente sociedad de consumo supuestamente permite. Por lo tanto, la película parece sugerir que Estela, Mario y otras personas de las clases bajas también pueden beneficiarse del declive de las jerarquías tradicionales, huyendo de los espacios sociales abusivos a través de las «fisuras en los bloques de la élite» (Daniels, 2013: 9). Así, el uso simbólico de los vehículos junto con el énfasis en el acceso a los bienes de consumo (como el televisor en la casa de Mario, o su reloj digital que sustituye al reloj de oro falso que el personaje lleva en la novela) plantean la cuestión de la movilidad social. Sin embargo, como Jennie Irene Daniels afirma acertadamente, aunque los personajes de la clase trabajadora tienen más capacidades de mover 


\section{Márton Árva}

en la película de Caiozzi, no disponen de «ningún lugar adónde ir», ya que ni su creciente consumo (imposible de financiar a largo plazo, como sugiere el robo), ni los persistentes abusos sexistas y racistas de la sociedad contemporánea, les permite una verdadera movilidad social (Daniels, 2013: 5-7).

Esta contradicción se expresa con claridad en el ya mencionado clímax de la película, en el que la muchacha acaba escapando de la mansión Ábalos. Al huir con Mario, Estela se libera de una situación social aparentemente ineludible: la de haber sido llevada a la casa por su tía sirvienta para que ella también trabaje como criada. Por esta razón, Daniels afirma que la solidaridad entre los marginados en el filme sirve como estrategia para aprovechar la crisis de la élite. Sin embargo, yo preferiría matizar esta observación remarcando las características del movimiento mismo que dicha fuga supone. En esta escena, Estela intenta huir con una pierna herida, dado que viene de revelar el robo, provocando que René la golpeara furiosamente y la empujara al suelo. Así, en contraste evidente con la escena anterior en la que los enamorados salen a recorrer la ciudad de Santiago en moto, esta vez Estela y Mario se tambalean a un ritmo dolorosamente lento. Don Andrés, a su vez, podría moverse más rápido para atraparlos y su única razón para no hacerlo es su decepción paralizante provocada por su desesperanza emocional. Por lo tanto, a mi juicio, esta secuencia, más que celebrar la solidaridad de la clase obrera, presenta un antagonismo entre personajes que se ven frustrados unánimemente por una transformación que los abruma a todos.

Por el contrario, los personajes que sin duda se benefician del cambio socioeconómico retratado son los que introducen los aspectos más debatidos del espíritu del libre mercado, adoptando los principios del neoliberalismo como «guía de toda acción humana» (Harvey, 2007: 3). Esto queda ilustrado por el sugerido paralelismo entre las relaciones humanas y los placeres consumistas. Aparte de su atraso tecnológico y su consiguiente exclusión del progreso y la prosperidad, el aislamiento de la villa de los Ábalos se expresa en términos de los ideales obsoletos de sus habitantes en lo concerniente al afecto. La reunión familiar en el cumpleaños de doña Elisita no solo enfatiza lo ajeno que es la mentalidad de los parientes al espíritu de la casa - mostrando a los invitados en su constante búsqueda de oportunidades de negocio y su terminología empresarial inglesa infiltrada en su vocabulario diario-, sino que también alude a sus relaciones amorosas entremezcladas. Los amigos y parientes se miran incansablemente coqueteando mientras discuten las posibilidades de 
explotar a sus sirvientes aún más. Así, la película sugiere que sus empresas económicas y sus relaciones románticas se organizan según una lógica similar: de manera espontánea y desregulada. Asimismo, Carlos presume de sus inversiones en la industria turística en paralelo con sus nuevos «proyectos» en el campo del amor.

En última instancia, la articulación más clara de los valores cambiantes es la secuencia en la que Carlos lleva a su viejo amigo en su coche nuevo y le muestra su casa lujosa. Durante unos deslumbrantes diez minutos, este viaje de pesadilla -ausente de la adaptación de Olhovich- no solo sumerge a don Andrés en el nuevo mundo del progreso, definido según la ideología de libre mercado, sino que le proporciona ocasiones para resumir explícitamente el choque irreconciliable de ideas en el centro de la película. Analizando cada pequeño detalle de su coche y la felicidad momentánea que estos le proporcionan, Carlos pasa despreocupadamente por delante de un viejo transeúnte empobrecido antes de aparcar finalmente el vehículo delante de la residencia de lujo. Además, entusiasmado por todos los muebles, aparatos eléctricos y comidas extranjeras que había adquirido ( $_{i}$ Tecnología demasiado sofisticada para este país de mierda!», exclama), no presta atención a su amigo que se aflige por su corazón roto. Andrés, a su vez, expresa su envidia por aquellos que pueden tener «aventuras descartables», señalando que su tragedia decisiva es desear «poesía», es decir, placer duradero en lugar de experiencias rápidamente consumibles. En consecuencia, el caballero reflexiona sobre el vacío que existe entre la pérdida de sus privilegios heredados y el hecho de no participar en los nuevos emprendimientos. Eso se ve anunciado literalmente cuando don Andrés afirma que no tiene nada delante, ni detrás. Sin embargo, irrevocablemente acomodado en el mundo consumista, el médico borracho, en lugar de ocuparse de los problemas planteados por el soltero retrógrado, juega eufóricamente con su mando a distancia multifuncional, maximizando la comodidad de su experiencia de consumo sin entrar en una discusión profunda. Así pues, más allá de poner de relieve los inconfundibles contrastes que se derivan de la transición a la democracia neoliberal (como las crecientes desigualdades sociales y las rupturas radicales con los antiguos modelos de organización social), esta secuencia también resalta la falta de comunicación y solidaridad entre los que glorifican este ideal de progreso y los que lo rechazan.

Como hemos visto, Caiozzi formula un relato sobre una transformación social e ideológica que cambia las jerarquías sociales, los deseos individuales, los imaginarios colectivos y los rituales 
cotidianos. Su adaptación de la novela de Donoso ilustra la expansión del ethos consumista en una serie de episodios significativos que se enfocan en los aspectos y escenarios de la vida contemporánea modificados por este fenómeno. Esta adaptación incluso señala con un guiño autoirónico que el cambio de valores y la propagación de nuevos patrones de comportamiento social no dejan intacto ni al cine mismo. Esto salta a la vista al comparar las diferentes versiones de la escena de la cita de Mario y Estela en el cine. El texto de Donoso se refiere a esta experiencia como la que cambia a Estela, convirtiéndola de una campesina inocente en un sujeto más autoconsciente y deseante. Si bien la novela describe la tentación del cine solo en la medida en que tiene lugar en una sala «inmoralmente oscura» (es decir, en un espacio social no controlado por un discurso moralizador tradicional), tanto Olhovich como Caiozzi detallan la experiencia cinematográfica misma que la criada y su amante tienen allí. En ambas versiones se puede deducir qué es lo que la joven pareja está viendo en la pantalla grande, dado que sus expresiones faciales y los sonidos indican indirectamente lo que se está desenvolviendo ante sus ojos. En la versión mexicana de 1976, preocupada por la Revolución fallida y la consiguiente inmovilidad social, la joven pareja se ve en la proyección de un melodrama nacional y la escena de su encuentro romántico se muestra de una manera extrañamente anacrónica, en la que los personajes inclinan sus cabezas sobre los hombros del otro con una sonrisa en sus rostros. Como el gesto evoca el estilo de actuación del cine clásico mexicano, la escena puede interpretarse como una agridulce alusión a una época en la que las ilusiones revolucionarias aún estaban vivas. Por otro lado, en la segunda adaptación que retrata la experiencia de vivir en tiempos de la globalización económica y cultural, Estela y Mario ven una película de acción de habla inglesa y beben Coca Cola. No obstante, la película proyectada resulta tan violenta y abrumadora que los personajes son incapaces de disfrutar de la cita y se quedan petrificados mirando a la pantalla con ojos fijos. Así pues, la versión de Caiozzi no solo registra el cambio de valores y discursos hegemónicos en el contexto de la globalización neoliberal, sino que también sugiere lúdicamente que el propio cine se ha convertido en un lugar de bombardeo consumista. Como estas escenas también subrayan, aunque la pantalla grande refleje realidades marcadamente distintas en contextos socio-históricos diversos, su función cultural de asistir a los espectadores a través de los cambios bruscos de su vida sigue siendo sustancial. 


\section{CONClusiones}

Este trabajo se ha propuesto analizar los diálogos entre el texto y los contextos ideológicos y discursivos en el caso de la novela Coronación y sus adaptaciones cinematográficas. Hemos encontrado que el argumento de la obra escrita por José Donoso, que relata el encuentro de una joven trabajadora doméstica con una familia aristocrática decadente en el microcosmos de una vieja mansión, ha sido propenso a articular tensiones y transformaciones socio-históricas, lo que se vio reconocido por distintos cineastas latinoamericanos trabajando en diferentes momentos y ambientes. Mientras que la novela misma hace referencia a la erosión de los privilegios aristocráticos tradicionales tras el surgimiento de una clase empresarial capitalista en el Chile bajo la modernización industrial a mediados del siglo XX, la adaptación de Sergio Olhovich enfatiza los conflictos subjetivos de su protagonista y relaciona el enloquecimiento de los personajes y su aislamiento frente a la realidad social con la represión estatal experimentada en México después de 1968. En última instancia, la película chilena de Silvio Caiozzi adapta la trama original al entorno de los inicios del nuevo milenio santiaguino y se aventura a presentar una estructura narrativa más cercana a la del texto literario de Donoso. En cierto sentido esta última adaptación de Coronación parece sugerir que «aunque las élites tecnológicas han reemplazado a la élite terrateniente de Andrés y Elisa, las estructuras de clase permanecen en su mayor parte intactas si comparamos los años 50 y 2000» (Daniels, 2013: 2).

El hecho de que el mismo argumento haya logrado encontrar su relevancia y su función cultural en los tres contextos distintos, permite sacar la conclusión que el motivo de la confrontación entre «maestros»y «sirvientes» puede inspirar estructuras narrativas propensas a abordar inflexiones socio-históricas y sus consecuencias tanto psicológicas e individuales, como colectivas y sociales. Puesto que tales situaciones narrativas reducen la distancia entre diferentes capas y clases de la sociedad, creando un encuentro entre "patrones» que procuran guardar sus privilegios y «empleados» que desean salir de la marginalización y la explotación, los argumentos de este tipo exponen un espacio simbólico capaz de acomodar motivos y asociaciones característicos de transformaciones socio-históricas en diferentes ambientes. En el caso particular de Coronación, este carácter del argumento se ve reforzado por los motivos donosianos del aislamiento, el enloquecimiento y la desintegración (Náter, 2007: 148-155), que unánimemente llaman la atención al conflicto entre el mundo interior de los personajes y sus condiciones sociales. 
Márton Árva

\section{BIBLIOGRAFÍA CITADA}

ACEVedo-Muñoz, Ernesto R. (2003), Buñuel and Mexico: the crisis of national cinema, Berkeley/Los Angeles, University of California Press.

ButTes, Stephen (2014), «Huaso Romance as Neoliberal Reform in Sebastián Silva's La Nana», Journal of Latin American Cultural Studies, 23/4, págs. 345-362.

Castillo-Feliú, Guillermo I. (1980), «Reflexiones sobre el perspectivismo en Coronación de José Donoso», Hispania, 63/4, págs. 699-705.

Cavallo, Ascanio, Pablo Douzet y Cecilia Rodríguez (2007), Huérfanos y perdidos: el cine chileno de la transición 1990-1999, Santiago de Chile, Uqbar editores.

Collier, Simon y William F. SATER (2004), A History of Chile, 1808 2002, Cambridge, Cambridge University Press.

DAniels, Jennie Irene (2013), «Elite in Crisis: The Marginalized as a Site of Resistance in La Ciénaga and Coronación», DeRLAS, 14/1, págs. 1-11.

Donoso, José (1984), Coronación, Santiago de Chile, Zig-Zag.

Donoso, Silvia Margarita (2016), «Caiozzi tras la huella de Donoso: La plasmación del ambiente ajado en Coronación.Una revisión a las relaciones entre cine y literatura a partir de un caso chileno», Organon, 31/61, págs. 103-116.

Galindo V., Óscar (2008), «Metatextos e imaginarios identitarios en la literatura chilena (1950-1970)», Estudios filológicos, 43, págs. 101-114.

García Riera, Emilio (1995), Historia documental del cine mexicano: 1974-1976, 17, Guadalajara, Universidad de Guadalajara.

GatTI, Giuseppe (2013), «De la literatura al cine: Isotopías fílmicas en Naturaleza muerta con Cachimba. La transposición fílmica de la nouvelle donosiana», Guaraguao, 17/42, págs. 29-50.

Godoy Gallardo, Eduardo y Haydée Ahumada PeÑa (2012), «La generación del 50: momento clave en la literatura chilena (En torno a dos antologías de cuentos: 1954-1959)», Anales de la literatura chilena, 13/18, págs. 103-116.

Harvey, David (2007), A Brief History of Neoliberalism, Oxford, Oxford University Press.

Kovács, András Bálint (2007), Screening Modernism: European Art Cinema, 1950-1980, Chicago, University of Chicago Press. 
La lucha de clases en Coronación de José Donoso y sus adaptaciones fílmicas

NÁTER, Miguel Ángel (2007), José Donoso: entre la esfinge y la quimera, Santiago de Chile, Cuarto Propio.

Ramírez Berg, Charles (1992), Cinema of Solitude: A Critical Study of Mexican Film, 1967-1983, Austin, University of Texas Press.

Richard, Nelly (2004), Cultural Residues: Chile in Transition, Minnesota, University of Minnesota Press.

Stam, Robert (2009), Teoría y práctica de la adaptación, México, UNAM.

VÁzQuez MANTeCón, Álvaro (2016), «El 68 cinematográfico», en M. Mestman (coord.), Las rupturas del 68 en el cine de América Latina, Buenos Aires, Akal, págs. 281-306.

Fecha de recepción: 10/12/20.

Fecha de aceptación: 09/02/21. 